\title{
Capital Expenditure Decisions and the Role of the Not-for-Profit Hospital: An Application of a Social Goods Model
}

\author{
John R.C. Wheeler and Jan P. Clement
}

In recent years, there has been considerable controversy over whether not-for-profit (NFP) and for-profit (FP) hospitals really differ from each other in meaningful ways. Specifically, the ongoing debate has concerned whether NFP hospitals pursue objectives that differ from the objectives of FP hospitals and, if so, whether these different objectives get translated into different sorts of behaviors. Although it is difficult to derive empirical support for hypothesized objective functions of NFP hospitals (Pauly 1987a), some research studies have suggested important substantive differences in the behavior of NFP and FP hospitals. These findings include production of more costly and higher priced care in FP hospitals (Gray 1986), better access in NFP hospitals (Gray 1986; Lee and Weisbrod 1977), more charity care in NFP hospitals (Gray 1986; Lewin, Eckels, and Miller 1988), and higher prices and profits in FP

John R.C. Wheeler, Ph.D. is Professor, Department of Health Services Management and Policy, School of Public Health, The University of Michigan, Ann Arbor. Jan P. Clement, Ph.D., is Assistant Professor at the Medical College of Virginia and Williamson Institute, Virginia Commonwealth University, Richmond. 
hospitals (Renn et al. 1985). Others have concluded that NFP hospitals are less efficient than FP hospitals after adjustment for tax subsidies (Herzlinger and Krasker 1987). Finally, some have reported that no important differences exist between the two ownership types (Sloan and Vraciu 1983).

This article is based on the argument that, whatever the research shows about differences in the behavior of FP and NFP hospitals, NFP hospitals -in order to justify the special treatment they receive, including exemption from income and property taxes and the right to issue tax-exempt bonds-ought to behave in a manner fundamentally different from FP hospitals. Several states and localities are, in effect, taking this normative position by challenging the traditional privileges enjoyed by NFP hospitals in situations where the hospitals are not demonstrating a sufficient social orientation in their behavior (Baldwin 1987; Nauert et al. 1988).

At the outset, one might ask whether it is reasonable to expect NFP hospitals to behave in a more socially oriented manner than FP hospitals under increasingly constrained environmental circumstances. It has been suggested that they are adopting and will have to continue to adopt the behavior of FP hospitals, sacrificing nonfinancial goals to assure financial viability (Jones, DuVal, and Lesparre 1987). The premise of this article is that, in spite of economic pressures, managers of NFP hospitals must ensure that significant differences continue to exist in the behavior of NFP hospitals as compared to FP hospitals and, further, that the communities these hospitals serve are clearly and accurately informed of the differences. Abandonment of nonfinancial objectives could well be a major step in the demise of the not-for-profit hospital sector (Foster 1987). To fulfill their roles with accountability to the communities they serve, and to justify their special treatment, managers of NFP hospitals must use decision criteria somewhat different from those of FP hospitals (Anthony and Herzlinger 1975).

This study addresses one decision that is important for all firms, the capital expenditure (investment) decision. This decision is especially critical to the NFP institution's ability to meet both its service and its financial objectives and, indeed, to its very survival in this era of restrictive prospective payment and increasing competition and rivalry. The literature on capital expenditure decision making for not-for-profit health care institutions has not reached a consensus on how these decisions should be made. As this article will show, differences exist both in the theoretical bases for decision criteria and in the technical decision tools to employ.

We propose a normative decision model that explicitly recognizes 
the necessity of both fiscal soundness and the achievement of nonfinancial objectives by NFP hospitals. Perspective on this issue is established first by examining the historical and current role of not-for-profit hospitals in society. This examination demonstrates the need to achieve nonfinancial objectives and provides a clear theoretical foundation for the model, something missing in much previous work. Before the investment decision-making model is presented, its context within the longrange planning process is established. Then, the proposed project evaluation decision model is presented. The model recognizes nonfinancial objectives while using standard tools of investment decision making. Unlike many previous models, the model presented here explicitly assigns values to nonfinancial goals. Although the model uses a specific definition of nonfinancial goals, it can easily be extended to other definitions such as "community benefits" (Seay and Sigmond 1989). The longterm planning and project evaluation methods also presented help to clarify and expand the discussions of previous authors and can be used by managers of not-for-profit hospitals to demonstrate the differences between their missions and accomplishments and those of for-profit institutions.

\section{THE ROLE OF NOT-FOR-PROFIT HOSPITALS}

In contrast to the purpose of for-profit firms, which is to maximize the wealth of owners, the establishment of not-for-profit firms has often been explained by certain characteristics of the output of the firm. ${ }^{1}$ Specifically, characteristics of the output necessitate the establishment of nonprofit firms to remedy government or contract failure.

Weisbrod $(1977,1988)$ argues that the United States economy is divided into three sectors: private for-profit, government or public, and private nonprofit. The existence of both the public and the nonprofit sectors stems from collective goods - those goods which by their natures provide positive externalities or benefits to the community as a whole. National defense and mosquito control are two traditional examples. Inherent in these goods is the "free rider" problem-those who do not pay can still consume the good. Therefore, private for-profit markets will fail to provide these goods in sufficient quantity. ${ }^{2}$

Government often intervenes in the markets for these goods, with financing compelled through taxation. Public programs that subsidize people's consumption of medical care services, such as Medicaid, are examples of such intervention. ${ }^{3}$ However, government is limited by vari- 
ous factors, especially political ones, in its ability to correct these markets, and will provide only the amount demanded by the median or mean voter (Weisbrod 1988). Nonprofit firms develop to satisfy the demand for collective goods among individuals whose tastes for them are above those of the median voter. Equity capital for these organizations is supplied largely by donations. ${ }^{4}$ By providing collective goods that benefit society but which both the private for-profit and the public sectors fail to provide, the NFP firm represents a "quasi-governmental response to forces that constrain the ability of democratic governments as political institutions to satisfy consumer demands for collective goods. ${ }^{5}$

Weisbrod's theory provides historical reasons why NFP firms exist, but it does not fully describe most NFP hospitals today. Modern NFP hospitals are mixed commercial NFP and social good-providing organizations, as Silvers and Kauer (1986) and Hansmann (1980, 1987) suggest. They derive most of their revenues from sales of services to private consumers, much as a for-profit firm does, while they also produce social outputs in the form of charity care, other services sold below cost, and unreimbursed medical research and education.

Some previous writers on the investment decision and the return on equity requirements of NFP hospitals have focused on one or the other aspect of this mixed social and commercial enterprise because of differing theoretical perspectives or the absence of an organized theoretical basis. For example, with their broad definition of the benefits of health care outputs, which is not based on economic or other behavioral theory, Berman and Weeks (1982) and Herkimer (1978) implicitly liken the entire NFP health care firm to a governmental entity. In their investment models, each output is treated as a social output because each benefits patients by saving lives, restoring health, improving convenience, and the like. In contrast, because Pauly (1986) assumes that donors may require minimal return for their donations, and that the form of these returns is more varied than just social outputs, in his world the NFP firm is primarily a commercial firm subject to the opportunities and constraints present in its local market. Social outputs play a relatively minor role. ${ }^{6}$

Other previous work is based on Weisbrod's theory, or other similar theories, although the theoretical foundation is not presented. Silvers and Kauer (1986) are more explicit than Conrad (1984) in incorporating the dual nature of the firm in their analyses, if not in a formal capital expenditure model. The capital enhancement role of for-profit firms, capital preservation of NFPs, and the capital consumption role of government in Long's (1982a, b) work are direct results of the types of 
outputs the firms produce. For example, government produces outputs that the private sector will not undertake because capital preservation or enhancement is not possible. Like Conrad, Long (1976) does not explicitly delve into the dual role of the NFP health care firm, but he does incorporate both functions in at least one of his capital expenditure models.

The structure of the modern NFP hospital has evolved to facilitate the production of both commercial and social goods. As we show later, the combination of two activities of the NFP hospital-one a private commercial NFP activity, similar to that of a credit union, and the other a quasi-governmental public sector activity-is central to the financial decision-making process of this hybrid firm. Social good production is facilitated through the establishment of a highly visible community resource that can serve as a vehicle for receiving and accumulating charitable contributions, governmental subsidies, and volunteer effort for the purpose of financing social activities. The NFP hospital may convert these resources into social outputs in the same period as they are received, or it may use the resources for social good production in later periods. Further, the hospital may be able to supplement these financing sources with profits from its commercial activities, where some of the revenues from commercial activities also come from community members.

From a finance perspective, these community-provided financing sources (donations, government subsidies, tax exemption, volunteer effort, and profits), if not consumed during the period they are received, provide equity financing for the NFP hospital. This equity financing is analogous to the equity financing of for-profit firms, which takes the form of common stock sales and retained earnings. And, as in the FP case, the suppliers of equity financing to the NFP hospital require a return on their money. ${ }^{7}$ Paying a return to capital suppliers ensures future inflows of capital as well as satisfying previous capital suppliers. The nature and requirements for this return are discussed later, under Social Outputs.

\section{LONG-RANGE FINANCIAL PLANNING}

All capital expenditure decision making must begin with the establishment of a long-range (three-to-five-year) financial plan based on the long-range strategic plan. Cleverley (1986) has described the long-range financial planning process in detail. Some aspects of the process are 
particularly important in the capital expenditure decision and therefore require discussion here.

Foremost in the development of the financial plan is the establishment of two targets: (1) the stock of assets needed to carry out the hospital's objectives for the future and (2) the target capital structure of the firm as reflected by the dollar values of long-term debt and equity. Planning begins by determining the magnitude of desired commercial and social activities of the firm in the future and projecting the necessary set of assets to carry out these activities. Determination of the mix of social and commercial activities will depend on the overall mission of the hospital and, as discussed later, on the sources of financing available for these activities. The change in assets between the current and projected balance sheets must be financed with a debt/equity mix that results in the target capital structure. The principal determinant of the feasibility of the long-range financial plan is the ability of the hospital to generate sufficient equity to support the desired assets while holding to the target financing ratio.

For planning purposes, the annual percentage change in the dollar value of equity from operating and nonoperating sources is the minimum return on equity (profit rate) required to create the retained earnings necessary to finance the new assets. Along with the cost of debt financing, it determines the discount rate to use in the capital expenditure decision, as described later.

The profit rate achievable is affected by the market power of the firm. If the NFP hospital possesses little market power, the target return on equity may have to be revised downward. Or, if projects cannot generate the required return on equity, the firm may have to adjust its asset expansion plans downward. Financial planning is always an iterative process. It may be necessary to revise programs, goals, or the target capital structure if the required profit rate is not feasible due to product market conditions.

The long-range financial plan is related to the adoption of individual projects in two specific ways: (1) it provides a framework within which to evaluate specific projects by explicitly stating the social and commercial missions of the hospital; and (2) it reflects the evaluations of specific projects by showing which ones the hospital intends to undertake. In this sense, there is an iterative process between project assessment and long-range financial plan development. Desired projects determine the ideal asset structure. The returns on these desired projects, and the availability of sources of financing, determine the feasibility of the projects and therefore of the ideal asset structure. 


\section{A METHODOLOGY FOR THE EVALUATION OF SPECIFIC PROJECTS}

In this section, a methodology for evaluating specific projects is presented. Like the approaches proposed by Long (1976, 1982a, b), and Conrad (1984), and the model implied by Silvers and Kauer (1986), it is based on the wealth-maximizing net present value (NPV) criterion recommended by financial economists for for-profit commercial enterprises. However, the methodology also draws on the theory of the notfor-profit firm, specifically the mixed social and commercial nature of the NFP hospital, and formalizes the two roles in investment decision making. In the model, both the commercial (cash) and social value created by the NFP hospital are quantified. Investment models proposed previously by other authors have incorporated this dual nature only informally and qualitatively (Berman and Weeks 1982; Herkimer 1978), or have not shown the effect of the roles on the components of the model in detail (Long 1976, 1982a, 1982b; Conrad 1984).

Presented next is a general description of the model, followed by detailed discussions of each model component and, finally, an elaboration of the decision criteria for the types of projects the NFP firm evaluates. The discussion focuses on decision situations in which a project can be evaluated independently, rather than in competition with another project. Extending the approach to the analysis of two or more mutually exclusive projects is straightforward.

\section{THE MODEL}

As part of the annual capital budgeting process, each project $j$ consistent with the mission of the hospital should be evaluated according to the following criteria:

$$
\Sigma_{t} C_{t} /\left(1+k_{w}\right)^{t}+\Sigma_{t} \mathrm{SO}_{t} /\left(1+k_{s}\right)^{t} \geqslant 0
$$

or

$$
N P V_{j}+N P S V_{j} \geqslant 0,
$$

subject to:

$\Sigma_{j} N P V_{j}+U D=0$,

$N P S V \geqslant 0$ for each $j$, 
where $C_{t}=$ the net cash flow generated by project $j$ in period $t$;

$k_{w}=$ the firm's commercial project discount rate;

$S O_{t}=$ the social output generated by project $j$ in period $t ;$

$k_{s} \quad=$ the social rate of time preference for social outputs; and

$U D=$ the value of unrestricted donations and donations for charity care received in year 0 .

The first term in Equation 1 is the net present value of cash flows $\left(N P V_{j}\right)$, which is the heart of the capital expenditure analysis of the for-profit firm. Projects having positive net present values increase the wealth of the firm's owners by increasing the monetary value of the firm. Many NFP hospitals have begun to use this criterion to evaluate capital investment projects.

The second term is what most clearly distinguishes capital expenditure decision making in the NFP hospital from that in the for-profit firm. It represents an assessment of the net present social value $\left(N P S V_{j}\right)$ of the investment received by suppliers of equity capital over the life of the project and reflects the interaction of financing with investment in the dual-purpose NFP firm. Note that in this model, unlike those of previous authors (Berman and Weeks 1982; Herkimer 1978), not all projects must create social value; the NFP hospital may undertake some purely commercial projects with social values of zero. The sum of the commercial and the social values created by each project must equal or exceed zero (Equations 1 and 2). To ensure the financial viability of the organization, however, the sum of the NPV of cash flows from all projects adopted in a given year, plus the value of unrestricted donations received in that year, must equal zero (Equation 3 ). ${ }^{8}$ In addition, any project affecting social value must affect it positively (Equation 4 ).

\section{Cash Flows $\left(C_{t}\right)$}

The process of valuing the cash flows of a project employs the same methodology as is appropriate for the for-profit firm, as described thoroughly in standard corporate finance textbooks. Therefore, we do not cover this process in any detail, but rather focus on how the results of this process, in combination with the social value analysis described previously, influence the capital expenditure decision.

As for the FP firm, the yearly net cash flows $\left(C_{t}\right)$ are the difference between cash inflows and cash outflows each year resulting from project adoption, where all cash flows are measured as differentials from the current levels. The outflows are composed of the initial outlay at time zero for the long-term assets of the project plus yearly operating out- 
flows, including expenditures for social good output. Among the inflows are reimbursements from third party payers, payments from individual patients, and salvage values of replaced assets.

An important source of cash inflows for some projects involving capital expenditures is funds donated for the specific purpose of financing the project. Such project-specific donations should be included among the cash inflows generated by the project, if in fact these donations would not be flowing to the firm in the absence of the project. This approach, which differs from that proposed by Long (1982a, 1982b), treats restricted donations as a form of revenues generated by the project, rather than financing for the general purposes of the firm. Further, it permits the NFP firm to adopt projects that generate no operating cash inflows, as long as the necessary capital and operating funds are provided by donors and the project is consistent with the mission of the firm.

\section{Social Outputs $\left(\mathrm{SO}_{t}\right)$}

Any project that produces social outputs must be evaluated to determine its net present social value (NPSV), an estimate of the magnitude of social value generated by the project. The social outputs produced each year are quantified in the numerator of the second term in Equation 1. In essence, equity capital suppliers receive dividends in the form of social outputs produced by the firm that are valued by the equity suppliers (donors and others). ${ }^{9}$ Suppliers of equity capital to the NFP firm never get their initial capital returned in the form of cash. Instead, they receive a return on or a return of equity over a finite or infinite period in terms of in-kind dividends.

These in-kind dividends take the form of services with social value to the community. Such services include charity care and other services, such as medical research or education, that cannot or, for some reason, do not pay their own way. Outputs sold to patients at a price equal to or greater than the full cost of production are not social outputs. Similarly, if the government purchases care directly for beneficiaries of a program or supports research, the social output is created by the governmental entity and not by the NFP hospital. ${ }^{10}$

As with the FP firm, the NFP firm may choose to forgo paying dividends during a period. It may choose to earn profits, which are retained by the firm to increase the stock of equity financing. ${ }^{11}$ Retained earnings permit the firm to generate greater levels of social value (dividends) in future years. The ultimate return on equity in the NFP hospital is the value of social goods produced in the current and future periods. 
The investment decision model discounts the dividends during the period in which they are provided as part of the valuation process.

The method proposed in this article adopts a theory-based, yet practical way to quantify social returns; it is an adaptation of the willingness-to-pay approach to the valuation of social programs in a cost-benefit analysis context. Our model contends that the value of the social outputs in the numerator of the second term of Equation 1 depends on the external benefits of the program to its financial supporters, which is represented by what the community members (donors and other suppliers of equity capital) are willing to pay for the services generated by a particular project. ${ }^{12}$

The practical problem that arises is in the estimation of community willingness to pay. When a hospital project produces services to some persons able to pay and to other persons unable to pay, the value of services provided to paying persons is captured in the amount they actually pay, provided that this amount is above some minimum that might be established as the marginal cost of production. This value is a commercial cash flow and should be included in the calculation of the NPV of cash flows term. The value of services provided to patients who cannot pay, which is the numerator of the NPSV term, can be estimated by computing the average net price paid by those persons who are able to pay. This approach is based on the crucial assumption that the amount actually paid by paying patients is a fair representation of the value of the services to the suppliers of equity capital to the firm. The validity of this assumption must be considered in each particular evaluation. Four points are worth including in such a consideration.

First, price is a fair measure of value only if one allows that the payer has the capacity to judge the true value of the service in question. Many observers of the health care system would disagree with this proposition because of the informational asymmetry between the provider and the purchaser. Others would argue that for the majority of health care services, the patient, in combination with his or her physician and third party payer, is reasonably well informed about the potential value of treatment decisions.

Second, the presence of insurance can result in price distortions and the paying of a price in excess of that which one would be willing to pay in the absence of insurance. Or, the existence of monopsony power in the form of large third party payers can also result in the establishment of a net price below the price that individual patients would be willing to pay and one that is often below the full cost of production. ${ }^{13}$

Third, the price paid will not represent the maximum price a person would be willing to pay if the seller is unable to extract all of the consumer surplus involved in the transaction. This assumption is not 
particularly crucial. To the extent that it is not valid, the approach we have suggested will provide a conservative estimate of the value of the service.

Fourth, the amount a paying patient is willing to pay may be more or less than the amount a donor or other equity supplier would be willing to pay. Here, it is important to note that our suggested approach embodies an explicit value judgment. We argue that, from the perspective of the community supporting the NFP hospital, the value of a service provided to persons unable to pay is equal to the value of that same service to persons having the means to pay. In this sense, we take an egalitarian approach to the evaluation of social programs produced by NFP firms. This approach has the danger of overvaluing social programs, with the resulting possibility that the firm will choose to adopt programs with social value insufficient to justify their cash costs.

It is also possible that the project generates services that are solely for social purposes, and not at all for commercial purposes. In such a situation, the service has no paying patients, or at least no patients paying a rate approximating a reasonable market price. The analysis may be able to employ prices paid for the same service at another hospital in a similar market circumstance. In this case, all of the caveats discussed in the preceding paragraphs apply. But to these we would add the caution about applying price in one market to value in another market.

To summarize, the suggested valuation method assigns monetary value to the social services produced using an estimate of the price that people would be willing to pay for the social services. The estimate of this price should come from observation of the price paid by persons with the means to pay, either for services from the subject hospital or from a hospital in another market.

In the special case where the hospital has received donations made for the specific purpose of supporting a proposed program, the estimation of social value described above must be adjusted. The value of the program to the donors is well represented by the amount of their donations. This value has already been included as a cash inflow of the program. Therefore, the social value of the program must be net of the dollar value of the restricted donations. Failure to make this adjustment would result in double counting of the value of the project to contributors.

\section{Discount Rate for Cash Flows $\left(K_{w}\right)$}

The discount rate for calculating the net present value of cash flows is the weighted average cost of debt and equity financing for the firm as a whole if the project is adopted, or

$$
k_{w}=w_{d} k_{d}+w_{e} k_{e}
$$


where

$k_{w}=$ the weighted average cost of capital;

$w_{d}=$ the proportion of debt in the capital structure after the project is adopted;

$k_{d}=$ the cost of debt;

$w_{e}=$ the proportion of equity in the capital structure after the project is adopted;

$k_{e}=k_{m}(1-T)$, the net cost of equity capital;

$k_{m} \quad=$ the risk-adjusted market rate of return; and

$T=$ the marginal tax rate of donors.

Other authors have elaborated on the cost of debt thoroughly (Brealey and Myers 1988; Copeland and Weston 1988). Here we elaborate on the cost of equity financing.

The required cash and noncash return on equity capital for NFP hospitals has been the subject of much debate (Silvers and Kauer 1986; Conrad 1984, 1986; Pauly 1986). The concept of a return on capital merely suggests that there is an opportunity cost when capital is used in one way rather than in another.

NFP firms are typically started with donated funds. As discussed previously, according to the social goods model, donors will contribute to a NFP firm for one or both of two reasons. First, they will donate if the firm pays out dividends in the current period in the form of social outputs having a value at least equal to the cash value of the donation. Or they will donate if the NFP firm provides dividends in future periods. When this equity is used to generate cash flows, a commercial purpose rather than the social purpose for which the equity was initially contributed, the firm must return the opportunity cost of those funds. Donors must be assured that the initial donation will grow at least at such a rate that its ability to purchase social dividends grows as fast as or more rapidly than the donor would be able to achieve through the next best alternative-the rate of return available in national financial markets after taxes $\left[k_{m}(1-T)\right]$ (Silvers and Kauer 1986; Long 1976; Conrad 1986). To that we would add a risk adjustment as detailed in Wheeler and Smith (1988).

This return must be earned whether the source of equity is donations or retained earnings. Retained earnings can be likened to capital appreciation in the standard investment model. The amount added to retained earnings in a given year is higher to the extent that dividends are not paid in that year. The required return each period in that model is based on the appreciated value of the investment. Thus, the tax-adjusted 
market-required rate of return is appropriately applied also to retained earnings. ${ }^{14}$

The equity growth rate specified by the hospital's long-range plan may exceed the tax-adjusted market return rate in some instances. If so, this planning-generated required rate of return should be used for $k_{e}$ instead of the market return. However, it is critical to note that this rate may be infeasible unless the NFP firm is very efficient, is subsidized by a governmental unit, or has some monopoly power. If these conditions do not exist, the long-range plan may have to be revised to a lower growth rate. In other words, the market evaluation of the firm is that it should not grow at its planned rate.

\section{Social Discount Rate $\left(k_{s}\right)$}

The social discount rate is the equivalent of return on equity in the for-profit firm except that the supplier of equity capital to the NFP firm expects in-kind dividends in the form of social outputs in perpetuity. ${ }^{15}$ The dividends generated over the life of a project by the NFP hospital must be discounted to the present time to show their value in today's dollars, which is the amount that donors would be willing to pay to receive them. There is a well-developed literature on the appropriate discount rate to use in evaluating social programs, dating back at least to Marglin (1963) and Baumol (1968). This literature develops the debate over whether the discount rate for social programs is different from the discount rate for private investment decision making. The context of the private NFP hospital is characterized by private financing of public goods, so that the issue of the appropriate social discount rate is perhaps even more complex than in the situation of public financing of a public good. The issue can be satisfactorily resolved by employing the arbitrage argument articulated by Silvers and Kauer (1986), Long (1976), and Conrad (1986). If the NFP hospital does not return dividends at a rate at least equal to the tax-and risk-adjusted return on the market portfolio, donors are better off investing their dollars in the market portfolio and using the proceeds to purchase social goods directly.

Pauly (1987b), in contrast, envisions a local market for donations that is separate from the national capital markets. If his contention is correct, the discount rate would be selected to reflect a localized social rate of time preference, or it may vary with the supply and demand for donations rather than the opportunity cost of the market return rate. Pauly suggests correctly that empirical examination of return rates is a logical next step in the debate. However, for purposes of capital expenditure analysis, we are persuaded by the arbitrage argument. Therefore, 
in calculating the present value of social programs, NFP firms ought to use a risk- and tax-adjusted opportunity cost of capital as perceived by the suppliers of equity capital.

\section{PROJECT ADOPTION OR REJECTION}

The NFP hospital evaluates three general types of projects with the model depicted in Equations 1-4: those that create only commercial value, those that create both commercial and social value, and those that create only social value. As discussed briefly now, the adoption criteria differ somewhat according to the type of project.

\section{Commercial Projects}

In the modern NFP hospital, some projects create only commercial value. Although other authors have recognized the dual nature of the NFP hospital, purely commercial projects have been ignored. For dual NFP firms, commercial projects with positive NPVs, as determined by evaluating the first term of Equation 1, should be adopted, because their cash rates of return exceed the discount rate. A project with a NPV of zero will generate cash equivalent to the return on capital necessary to satisfy capital suppliers and meet the long-range financial plan of the firm. A project generating a positive net present value is, in effect, producing a surplus equity (and cash) contribution, which may be used to support other projects with social value. Both Long (1976) and Conrad (1984) point out that social outputs cannot be produced unless a positive cash return on equity is earned.

\section{Mixed Projects}

Some positive NPV projects will by their nature generate social value in addition to cash (commercial) value. As with the commercial projects, if these projects contribute non-negative NPVs to the firm, they should be adopted. However, some of these projects will generate negative NPVs, especially because social output expenditures are cash outflows. In these cases, there are two further criteria for adoption.

First, if the social value of the project exceeds the negative NPV, or cash cost, the project is a candidate for adoption. In this case, the project is desirable because the aggregate value created is positive; that is, the cost in value to the firm is less than the benefit in value given to the 
community in dividends. Projects that generate less social value than the net present cash cost to the firm should be rejected. They use up more value in the firm than they provide in value to the community. Note that if $k_{e}$ is increased to reflect growth plans that exceed the market rate of return, fewer commercial and social projects will be accepted because fewer projects will satisfy the higher rate of return criterion.

The second criterion is shown in Equation 3; the constraint imposed on the adoption of "worthwhile" negative NPV projects is that the aggregate net present value of all projects adopted in a single period must be equal to zero. Thus, the adoption of any negative NPV project is dependent upon the adoption of positive NPV projects during the same planning period; that is, the firm will be able to adopt negative NPV projects while achieving its target financing structure only if sufficient excess cash is generated by positve NPV projects. Failure to adhere to this constraint will mean that the firm will be financing community dividends through sacrificing its ability to produce services (and dividends) in the future.

An exception may occur when the NFP hospital knowingly approves a partially liquidating dividend (Long 1982a, b). When this occurs, donors receive a return of their initial investment, as well as dividends, in the form of in-kind services. Some part of the initial investment is returned in the sense that the equity in the firm is reduced consciously by the decision to produce additional social outputs.

The constraint that the total NPV of all of the adopted projects equals zero agrees with Long's (1976) normative position that NFP firms are capital preservers. It does require that some projects with high NPVs subsidize some projects generating social value but little cash value. But this is different from requiring that each project earn sufficiently high return to provide funds for social outputs.

Hence, the essence of the NFP hospital lies in its facilitation of cross-subsidization (through donations, which transfer wealth, and through commercial projects) both to support the provision of services to persons who cannot pay and to support the production of services that, in a strict market sense, can not pay their own way.

\section{Social Projects}

Finally, a few projects may create no cash value at all. As with the mixed projects, they should be adopted only if sufficient positive NPV is created by the commercial or mixed projects so that Equation 3 is satisfied. In this way, capital is preserved, not consumed. 


\section{DISCUSSION}

The capital expenditure/investment model developed in this article demonstrates that investment and financing are not separate decisions when the NFP hospital produces both commercial and social outputs. Both the cash and social value of investments are quantified in the model, which is derived from economic theories regarding the role of NFP firms and valuation of social outputs. The model differs from previous discussions of capital expenditure decisions in its theoretical basis, its explicit valuation of social outputs, and the interaction of investment and financing when donations are the source of financing. We also show its link to the long-range financial planning process.

As is demonstrated by the model, social outputs can be precisely defined and must be valued and reported to the equity capital suppliers and the public if NFP hospitals are to demonstrate their "worthiness" of the special tax treatment they receive. Further, it will harm the retention of these benefits to claim that the benefits of NFP hospitals cannot be quantified (Jones, DuVal, and Lesparre 1987) or that every output produced by NFP hospitals is a social output (Berman and Weeks 1982). By employing the model developed here, managers of NFP hospitals can ensure their pursuit of missions different from those of FP hospitals and can demonstrate quantitatively the differences to the communities they serve. The model is generalizable to broader definitions of social outputs, such as community benefits but, again, we caution against imprecise or all-encompassing definitions of these outputs.

Implicit in this proposed methodology is the process of cross-subsidization. Cross-subsidization within an institution consists of supporting losses on those services that generate negative cash returns, with the profits on those services with positive cash returns or with donations. In economic terms, it is a transfer of wealth from those paying for the positive-return services to those receiving and perhaps paying for the negative-return services. The production of negative NPV services is basic to the existence of tax-exempt nonprofits-to facilitate the provision of services to the community that would not otherwise be provided. The board, in making strategic decisions, is faced with the constraint that the positive-return services support the negative-return services, or that the returns sum to zero. The board's fiduciary duty to preserve the assets of the organization requires that this overall NPV not be less than zero.

The expansion of case-based prospective payment and of discounted prices negotiated with some purchasers of care in which no return on equity is allowed has substantially limited hospitals' ability to 
cross-subsidize. Tight payment systems reduce margins, thereby eliminating support for negative margin services, with the likely result that negative cash return services will not be undertaken. Such a result would be most unfortunate. It would necessitate either increased direct financing by the public sector or reduced provision of services to society. Given the political and financial constraints on the public sector, service reductions are the most likely outcome.

A corollary to this argument is that if the NFP hospitals behave like for-profits in their capital expenditure decision making in order to improve financial performance, the same result will follow. By reducing the social benefits they provide to society, NFPs will face the loss of favorable tax treatment, as perhaps they should. It is also likely that the supply of equity financing would diminish (Smith, Wheeler, and Clement 1990). The challenge to nonprofit health care providers now and in the future will be to achieve both their financial and nonfinancial objectives.

\section{ACKNOWLEDGMENTS}

We are grateful for the comments of Rich Foster, Dean Smith, Jim Highland, Peter Wilson, Vivian Valdmanis, and an anonymous reviewer.

\section{NOTES}

1. Although FP firms may pursue objectives in addition to the wealth maximization objective, the discipline of the equity market makes it infeasible to pursue them at the expense of wealth maximization.

2. The economic theory underlying the concept of public goods is summarized in Musgrave and Musgrave (1973).

3. For an excellent theoretical discussion of external benefits and the appropriate public response in the health care context, see Pauly (1971).

4. By adopting Weisbrod's (1977) social good model, we assume away other motivations for donations, such as having the option of one's own care if needed in the future.

5. Weisbrod (1977), p. 2.

6. There is no formal investment model presented in Pauly (1986).

7. See Smith, Wheeler, and Clement (1990) for a theoretical presentation of the return required by suppliers of NFP equity.

8. In any period, the total net present value of all projects adopted, plus unrestricted donations, may exceed or be less than zero. For capital to be preserved in the long run, and for the firm to maximize the value of services provided to the community, the NPV of all projects will sum to zero. 
9. Long (1976) was one of the first to conceptualize social outputs as community dividends.

10. Quantification of in-kind dividends can be accomplished by several methods. One way, recommended for governmental programs, is in terms of the improvements in health status that they produce. This approach requires the development of quantitative measures of health improvements, such as reductions in mortality or morbidity or improvements in the quality of life of patients. Torrance (1986) has detailed one technique for developing such a quantitative measure of health outcome, called Quality-Adjusted Life Years (QALYs), which is based on health state utilities. This approach also requires assignment of a dollar value to the measure of the health status. Our view is that, although the QALY method may be conceptually superior to other methods, in most cases it is impractical for a single firm to estimate a quantitative measure of the health effects of its proposed projects and to attach a dollar value to that measure in a consistent and nonarbitrary manner.

11. Silvers and Kauer (1986) argue that it is inappropriate for NFP hospitals to earn a return on retained earnings because donors are deprived of the tax benefits from new donations. This conclusion, however, is inconsistent with their analysis of the required rate of return in which the donor donates all of her tax benefits to the NFP.

12. The approach is implicit in the arguments of Long (1976) and Silvers and Kauer (1986).

13. Price reductions based on sliding fee scales or price discrimination are social output choices made by the firm. The resulting lower prices should in general not be used to estimate willingness to pay.

14. See note 11.

15. Some NFP firms pay self-liquidating dividends (Long 1982a, b) in the sense that they consciously adopt projects which, taken together, result in negative NPV. Some donors give to NFP firms with the expectation that these firms will pay self-liquidating dividends.

\section{REFERENCES}

Anthony, R. N., and R. E. Herzlinger. Management Control in Nonprofit Organizations. Homewood, IL: Richard D. Irwin, Inc., 1975.

Baldwin, M. F. "Legislatures, Agencies Debating Whether Not-for-Profit Hospitals Deserve Their Tax-Exemption." Modern Health Care 17, no. 21 (May 1987): $34-42$.

Baumol, W. J. "On the Social Rate of Discount." American Economic Review 58, no. 4 (1968): 788-802.

Berman, H. J., and L. E. Weeks. The Financial Management of Hospitals. 5th ed. Ann Arbor, MI: Health Administration Press, 1982.

Brealey, R., and S. Myers. Principles of Corporate Finance. 3rd ed. New York: McGraw-Hill, 1988.

Cleverley, W. Essentials of Health Care Finance. 2nd ed. Rockville, MD: Aspen, 1986. 
Conrad, D. A. "Returns on Equity for Not-for-Profit Hospitals: A Commentary and Elaboration." Health Services Research 21, no. 1 (April 1986): 17-20.

- - "Returns on Equity to Not-for-Profit Hospitals: Theory and Implementation." Health Services Research 19, no. 1 (April 1984): 41-63.

Copeland, T. E., and J. F. Weston. Financial Theory and Corporate Policy. 3rd ed. Reading, MA: Addison-Wesley Publishing Company, 1988.

Foster, R. W. "Hospitals and the Choice of Organizational Form." Financial Accountability and Management 3, no. 4 (Winter 1987): 343-65.

Gray, H. B., ed. For-Profit Enterprise in Health Care. Washington, DC: National Academy Press, 1986.

Hansmann, H. "Economic Theories of Nonprofit Organization." In Not-for-Profit Sector. Edited by W. W. Powell. New Haven, CT: Yale University Press, 1987.

. "The Role of Nonprofit Enterprise." The Yale Law Journal 89, no. 4 (April 1980): 835-901.

Herkimer, A. G. Understanding Hospital Financial Management. Germantown, MD: Aspen, 1978.

Herzlinger, R., and W. S. Krasker. "Who Profits from Nonprofits?" Harvard Business Review 63, no. 1 (January-February 1987): 93-106.

Jones, S. B., M. K. DuVal, and M. Lesparre. "Competition or Conscience? Mixed-Mission Dilemmas of the Voluntary Hospital." Inquiry 24, no. 2 (Summer 1987): 110-18.

Lee, A. J., and B. A. Weisbrod. "Collective Goods and the Voluntary Sector: The Case of the Hospital Industry." In The Voluntary Nonprofit Sector. Edited by W. A. Weisbrod. Cambridge, MA: Harvard University Press, 1977.

Lewin, L. S., T. J. Eckels, and L. B. Miller. "The Provision of Uncompensated Care by Not-for-Profit Hospitals." New England Journal of Medicine 318, no. 18 (1988): 1212-15.

Long, H. W. “Asset Choice and Program Selection in a Competitive Environment, Part 1." Healthcare Financial Management 12, no. 7 (July 1982a): 40-54.

- "Asset Choice and Program Selection in a Competitive Environment, Part 2." Healthcare Financial Management 12, no. 8 (August 1982b): 34-50.

- "Investment Decision-Making in the Health Care Industry: The Future." Health Services Research 14 (Fall 1979): 183-205.

- "Valuation as a Criterion in Not-for-Decision-Making." Health Care Mangement Review 1, no. 3 (Summer 1976): 34-52.

Marglin, S. A. "The Social Rate of Discount and the Optimal Rate of Investment." Quarterly Journal of Economics 77, no. 1 (1963): 95-112.

Musgrave, R. A., and P. B. Musgrave. Public Finance in Theory and Practice. New York: McGraw-Hill, 1973.

Nauert, R. C., A. B. Sanborn, III, C. F. Mackelvie, and J. L. Harvitt. “Hospitals Face Loss of Federal Tax Exempt Status." Healthcare Financial Management 42, no. 9 (September 1988): 48-58.

Pauly, M. V. Medical Care at Public Expense. New York: Praeger Publications, 1971.

- "Nonprofit Firms in Medical Markets." American Economic Review 77. no. 2 (1987a): 257-62.

. "Paying Returns on Equity to Not-for-Profit Hospitals-Some Futher Thoughts." Health Services Research 22, no. 2 (June 1987b): 271-75. 
- "Returns on Equity for Not-for-Profit Hospitals." Health Services Research 21 , no. 1 (1986): 1-16.

Renn, S. C., C. J. Schramm, J. M. Watt, and R. A. Derzon. "The Effects of Ownership and System Affiliation on the Economic Performance of Hospitals." Inquiry 22, no. 3 (Fall 1985): 219-36.

Seay, J. D., and R. M. Sigmond. "Community Benefit Standards for Hospitals: Perceptions and Performance." Frontiers of Health Services Management 5, no. 3 (1989): 3-53.

Silvers, J. B., and R. T. Kauer. "Returns of Equity for Not-for-Profit Hospitals: Some Comments." Health Services Research 21, no. 1 (April 1986): 21-28.

Sloan, F. A., and R. A. Vraciu. "Investor-Owned and Not-for-Profit Hospitals: Addressing Some Issues." Health Affairs 12, no 1. (Spring 1983): 25-37.

Smith, D. S., J. R. C. Wheeler, and J. P. Clement. "Donations and the Behavior of Nonprofit Firms." Unpublished manuscript. University of Michigan, 1990.

Torrance, G. W. "Measurement of Health State Utilities for Economic Appraisal." Journal of Health Economics 5, no. 1 (March 1986): 1-30.

Weisbrod, B. A. The Nonprofit Economy. Cambridge, MA: Harvard University Press, 1988.

The Voluntary Nonprofit Sector. Lexington, MA: Lexington Books, 1977.

Wheeler, J.R. C., and D. G. Smith. "The Discount Rate for Capital Expenditure Analysis in Health Care." Health Care Management Review 13, no. 4 (Spring 1988): $43-51$. 